\title{
Research on the "No-Typhoon July" in 2020 and Typhoon Frequency Variations in July in Recent 70 Years
}

\author{
Xiaoxu Qi \\ School of Atmospheric Sciences, Nanjing University of Information Science and Technology, Nanjing, China \\ Email: xiaoxuqi1@126.com
}

How to cite this paper: Qi, X. X. (2021). Research on the "No-Typhoon July" in 2020 and Typhoon Frequency Variations in July in Recent 70 Years. Journal of Geoscience and Environment Protection, 9, 75-83. https://doi.org/10.4236/gep.2021.91006

Received: October 9, 2020

Accepted: January 19, 2021

Published: January 22, 2021

Copyright $\odot 2021$ by author(s) and Scientific Research Publishing Inc. This work is licensed under the Creative Commons Attribution International License (CC BY 4.0).

http://creativecommons.org/licenses/by/4.0/

\begin{abstract}
By using China National Climate Center's 74 circulation characteristics, DERF2.0, BCC-CSM models and Wenzhou Typhoon Network data, and using linear regression, correlation coefficients and other research methods, the variations about typhoon frequency in July from 1951 to 2020 and the large-scale circulation system in July 2020 are analyzed. The results show that 1 ) in the recent 70 years, the frequency of typhoon generation has slowly decreased, while the frequency of landing typhoons in China has slowly increased; 2) typhoon frequency has varying degrees of negative correlation with the intensity of subtropical high in different regions of the northern hemisphere, especially with the area index and intensity index of the South China Sea subtropical high; 3) in July 2020, the area and intensity of the subtropical high in the Northwest Pacific were abnormally large and strong. Easterly winds prevailed in the tropics, and the cross-equatorial airflow was weak, resulting in a severe reduction in the frequency of typhoon generation, leading to "no-typhoon" events.
\end{abstract}

\section{Keywords}

No-Typhoon July, Typhoon Frequency, Subtropical High, Atmospheric Circulation

\section{Introduction}

Typhoon generally refers to a low-pressure vortex generated on the tropical or subtropical ocean surface. It is a powerful and deep tropical weather system. The Northwest Pacific region is the region with the most frequent and active typhoons. China is one of the countries most seriously affected by typhoons. Ty- 
phoon research has attracted more and more attention from scientific and technological workers (Su et al., 2020; Liu et al., 2020). This research aims to explore the typhoon frequency changes in July from 1951 to 2020, reveal the characteristics of the atmospheric circulation on a monthly scale, analyze the interaction between the atmospheric circulation index and the typhoon frequency, and make a Mechanism analysis for the "no-typhoon" event in July 2020.

Previous studies on typhoons mainly used quarterly or inter-annual changes as the time scale for studying typhoon frequency. He and Gong (2002) found that since 1980, significant inter decadal changes have occurred in the Northwest Pacific, and the subtropical high has expanded, strengthened and moved southwest. This change caused an abnormal anticyclonic circulation from the South China Sea to the Western Pacific. Bengtsson et al. (2007) found through model research that the number of typhoons will show a long negative growth trend in the 21st century. Zheng et al. (2013) pointed out that when the intensity of the subtropical high weakens, the ridge line becomes northerly, and the main body moves eastward, the monsoon trough deepens eastward to $160^{\circ} \mathrm{E}$, which is conducive to the formation of typhoons in low-latitude sea areas east of $150^{\circ} \mathrm{E}$. Lu et al. (2018) found that the frequency of typhoons entering the East China Sea from 1951 to 2015 has obvious inter annual and inter decadal trends. Camp et al. (2019) pointed out that there was only a weak correlation between the WPSH (Western Pacific Subtropical High) index and the typhoon frequency observed in East Asia from June to November.

This study will analyze the frequency anomalies of typhoons from the following three aspects: 1) generating statistics on the frequency of typhoons and landing typhoons in China; 2) analyzing the correlation between typhoon frequency and atmospheric circulation; and 3) characteristics of atmospheric circulation in the middle and lower troposphere analysis. Compared with previous studies, this study starts to analyze the variation of typhoon frequency from the inter-monthly scale.

\section{Data and Methods}

\subsection{Data}

This study uses 74 circulation characteristics of the National Climate Center of China, the second-generation product of monthly dynamic extended ensemble prediction (DERF2.0) and the second-generation seasonal prediction air-sea coupled model (BCC-CSM) data, and the typhoon number landing on the Wenzhou Typhoon Network data.

1) The 74 circulation characteristic data used in this study are from the Climate System Diagnostic and Prediction Room of China National Climate Center (Hu et al., 2020). The start time of the data is January 1951 and the end time is December 2016.

2) The statistics of typhoon numbers and landing data used in this study are summarized on the Wenzhou Typhoon website (http://www.wztf121.com). Wenz- 
hou Typhoon Network is a website established by the Wenzhou Meteorological Bureau of China. It provides the latest typhoon information and related weather data such as temperature field, wind field, cloud map, etc., so that the government and the public can track the typhoon trend and make disaster prevention and mitigation work in advance.

3) The upper tropospheric situation field data used in this study is derived from the second-generation product of the extended set of monthly dynamic forecasts (DERF2.0) and the second-generation seasonal forecast air-sea coupled model (BCC-CSM) of the China National Climate Center. The second-generation Dynamic Extended Range Forecast operational system version 2.0 (DERF2.0) of the National Climate Center of China Meteorological Administration is established based on the atmospheric circulation spectrum model, providing the ten-day and monthly average circulation situation and meteorological elements in the next 40 days. In 2014, based on the second-generation climate system model, the BCC_CSM1.2 model was developed for extended-range forecasting, and the model back calculation data was submitted to participate in the international S2S prediction plan (Zhang et al., 2019; Wu et al., 2013).

\subsection{Methodology}

This study uses the research methods of unary linear regression, Pearson correlation coefficient and anomaly to reveal the distribution law, changing inducements and abnormal fluctuations of typhoon frequency in July.

1) This study uses a univariate linear regression method to study the distribution of typhoon frequencies from 1951 to 2020. One-variable linear regression refers to the use of one variable from two linearly correlated variables to estimate another variable. The former is called the control variable and the latter is called the observed variable. The univariate linear regression model establishes the following linear equation form:

$$
y=\alpha+\beta x
$$

where, $y$ denotes the observed variables, $x$ denotes the control variables, $\alpha$ and $\beta$ denote the parameters.

By counting the time series values between two variables, the parameters in the model are obtained, and then the values of the model and the control variables are used to calculate the values of the observed variables (Luo, 2016). This study uses the residual sum of squares to test the fit of the unary linear regression. The residual sum of squares uses the sum of squared deviations between the true value of the observed variable and the corresponding estimated value to measure the total deviation of all data.

2) This study used the Pearson correlation coefficient research method. Pearson correlation coefficient is used to measure the linear relationship between two variables. Based on the deviation of the two variables from their respective averages, the degree of correlation between the two variables is reflected by multiplying the deviations of the two variables. The Pearson coefficient focuses on the 
linear single correlation coefficient ( $\mathrm{He}$ et al., 2012). When the correlation coefficient is -1 , it means that the two variables are completely negatively correlated; when the correlation coefficient is +1 , it means that the two variables are completely positively correlated. When the correlation coefficient is 0 , it means that the variables are not correlated. The specific calculation formula is as follows:

$$
r(X, Y)=\frac{\operatorname{Cov}(X, Y)}{\sqrt{D(X)} \sqrt{D(Y)}},
$$

where, $X$ and $Y$ denote different variable series, $r(X, Y)$ denotes correlation coefficient, $\operatorname{Cov}(X, Y)$ denotes co-variance of $X$ and $Y, D(X, Y)$ denotes co-variance of $X$ and $Y$.

3) This research uses anomalous research methods. The anomaly represents the difference between the individual data in the variable series and the average value, and is divided into positive anomalies and negative anomalies. The anomaly value is mainly used to determine the vibration deviation of the data in a certain period or time from the long-term average value of the physical quantity, and is an indicator to test whether individual data deviates from the general regularity. The specific calculation formula is as follows:

$$
x=x_{i}-x_{\text {ave }}
$$

where, $x$ denotes the gap between actual data and average data, $x_{i}$ denotes actual data, $x_{\text {ave }}$ denotes average data.

\section{Results and Analysis}

\subsection{Changes in Typhoon Frequency in July in the Recent 70 Years}

Since the record of typhoons in 1951, 283 typhoons in the Northwest Pacific have occurred in July, 130 typhoons has landed in China, accounting for $45.9 \%$ of the total, that is, nearly half of typhoons landed in China. The overall number of typhoons has a slight downward trend. However, the number of typhoons landing in China has a slight upward trend.

From Figure 1(a), it can be seen that the number of generated typhoons in July is in large fluctuations. The frequency of typhoons is mainly concentrated in 3 - 5 per year, with an average of 4.2 typhoons per year. In abnormal years, for example, 8 typhoons were generated in 1967, 1971, 1994, and 2017, and 1 typhoon was generated in 1954, 1957, 1985, and 1998. The frequency of typhoons is very different.

It can be seen from Figure 1(b) that most of the typhoons that landed in China in July are concentrated in the interval 1 - 3 per year, and the average number of typhoons generated per year is 1.7. Among them, the number of typhoons that landed in China in July 2001 reached 5, and there were no typhoons that landed in China in 1951, 1954, 1955, 1975, 1997, 1999, and 2020. There is a phenomenon that typhoon did not land in China in a certain month during the active typhoon period, which is called "no-typhoon" event. According to statistics, "no-typhoon" in July has a cyclical pattern of about 20 years. 


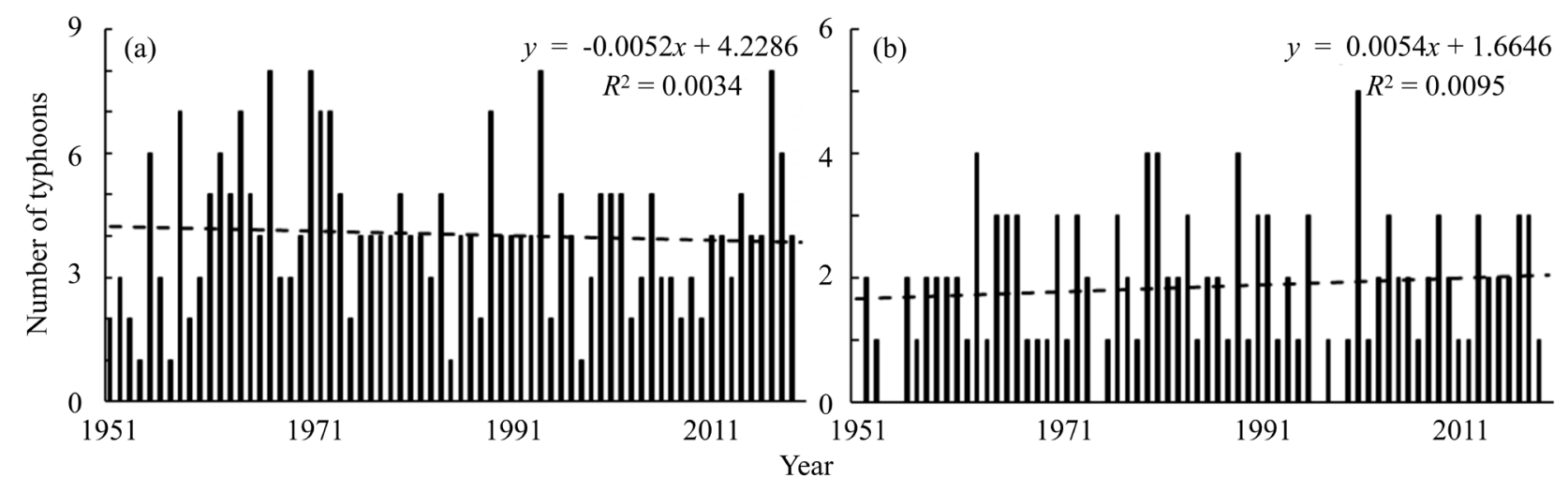

Figure 1. The frequency of typhoons from 1951 to 2020 (a. typhoons generated; b. typhoons landed).

\subsection{Correlation Analysis between Frequency of Typhoon Generation in July and Atmospheric Circulation}

This paper uses 74 circulation characteristic data from 1951 to 2016 to conduct correlation tests one by one, and select the following relatively significant characteristic indexes from them.

After comparing 74 circulation characteristic quantities, the absolute value of the correlation coefficient obtained in this study at the level of 0.01 did not exceed 0.5. This indicates that the subtropical high system and the India-Burma trough system have a certain correlation with the frequency of typhoon generation, but it has not yet reached the closely related level, which is basically consistent with the study of Camp et al. (2019).

Through the correlation coefficient test, this study found that the subtropical high system circulation index of different scales and regions has a relatively good correlation with the frequency of typhoon generation. Among them, only the westward extension of the western Pacific subtropical high ridge has a positive correlation with the frequency of typhoon generation, which is 0.357 , that is, the more easterly the ridge point is, the greater the frequency of typhoon generation. The other circulation indexes are all negatively correlated.

It can be seen from Table 1 that the subtropical high system in the northern hemisphere has an obvious negative correlation with the frequency of typhoon generation. The subtropical high system in different regions has a synergistic effect, and its specific impact on the typhoon is different from the location of the Northwest Pacific. The farther the subtropical high region is from the Northwest Pacific region, the worse the correlation between the circulation index and the frequency of typhoon generation in the region. Among these systems, the influence of the South China Sea subtropical high system is particularly significant. The correlation coefficient of the subtropical high intensity index reaches -0.405 , and the correlation coefficient of the subtropical high area index reaches -0.369 . When the subtropical high index increases, an anticyclonic circulation appears over the northwest Pacific, which is not conducive to the formation and development of typhoons. 
Table 1. Correlation coefficient table of typhoon frequency and circulation index.

\begin{tabular}{lc}
\hline \multicolumn{1}{c}{ Circulation Index } & Correlation coefficient \\
\hline West Pacific Subtropical High Ridge Point & $0.357^{\star *}$ \\
North American Subtropical High Intensity Index $\left(110^{\circ} \mathrm{W}-60^{\circ} \mathrm{W}\right)$ & $-0.324^{\star *}$ \\
North American Atlantic Subtropical High Intensity Index $\left(110^{\circ} \mathrm{W}-20^{\circ} \mathrm{W}\right)$ & $-0.335^{\star *}$ \\
Indian - Burmese tank $\left(15^{\circ} \mathrm{N}-20^{\circ} \mathrm{N}, 80^{\circ} \mathrm{E}-100^{\circ} \mathrm{E}\right)$ & $-0.340^{* *}$ \\
North Africa Atlantic North American Subtropical High Intensity Index & $-0.341^{\star *}$ \\
$\left(110^{\circ} \mathrm{W}-60^{\circ} \mathrm{E}\right)$ & $-0.352^{\star *}$ \\
Northern Hemisphere Subtropical High Intensity Index $\left(5^{\circ} \mathrm{E}-360^{\circ}\right)$ & $-0.369^{\star *}$ \\
South China Sea Subtropical High Area Index $\left(100^{\circ} \mathrm{E}-120^{\circ} \mathrm{E}\right)$ & $-0.405^{\star *}$ \\
South China Sea Subtropical High Intensity Index $\left(100^{\circ} \mathrm{E}-120^{\circ} \mathrm{E}\right)$ &
\end{tabular}

Note: ${ }^{\star *}$ indicates a significant correlation at the 0.01 level (two-sided).

It is worth noting that the intensity of the India-Burma trough has a strong negative correlation with the frequency of typhoons. The India-Burma trough is located in South Asia, and objectively has brought a blocking effect to the western extension of the subtropical high in the Pacific Ocean. When the intensity index of the India-Burma trough decreases, that is, when the India-Burma trough strengthens, the Pacific subtropical high weakens accordingly, and the westward extension is not obvious, which promotes the generation of typhoons.

\subsection{Analysis of the Atmospheric Circulation Characteristics of the "No-Typhoon" Event in July 2020}

Figure 2 comes from the second-generation product of the extended set of monthly power forecasts of China National Climate Center (DERF2.0). It indicates that there will be a wide range of positive height anomalies in Asia and the Western Pacific in July 2020. East Asia and the Western Pacific, the Arctic Circle and Western Siberia will have strong signals of 4 - 8 levels, far exceeding the average level of previous years, corresponding to the strong Northwest Pacific subtropical high system. What is more, all other regions in Asia have experienced a rise in potential height, which means that the northeast hemisphere will be in a relatively high-pressure large-scale circulation field in July 2020.

Since July of this year, the Northwest Pacific Subtropical High has been abnormally westward, southerly, larger in area and stronger in intensity. Since the source of typhoon generation is controlled by the subtropical high pressure, its range is generally sinking airflow, and tropical convection activities are suppressed. Therefore, typhoon generation is extremely difficult and the frequency of generation will be significantly reduced.

Figure 3 comes from China National Climate Center's second-generation seasonal forecast air-sea coupled model (BCC-CSM). As shown in Figure 3, in the tropical region of $110^{\circ} \mathrm{E}-180^{\circ}$ in July this year, the $850 \mathrm{hPa}$ altitude field is basically east wind. The low-latitude zonal westerly airflow weakened, and the cross-equatorial airflow was weaker than that of previous years. The power 


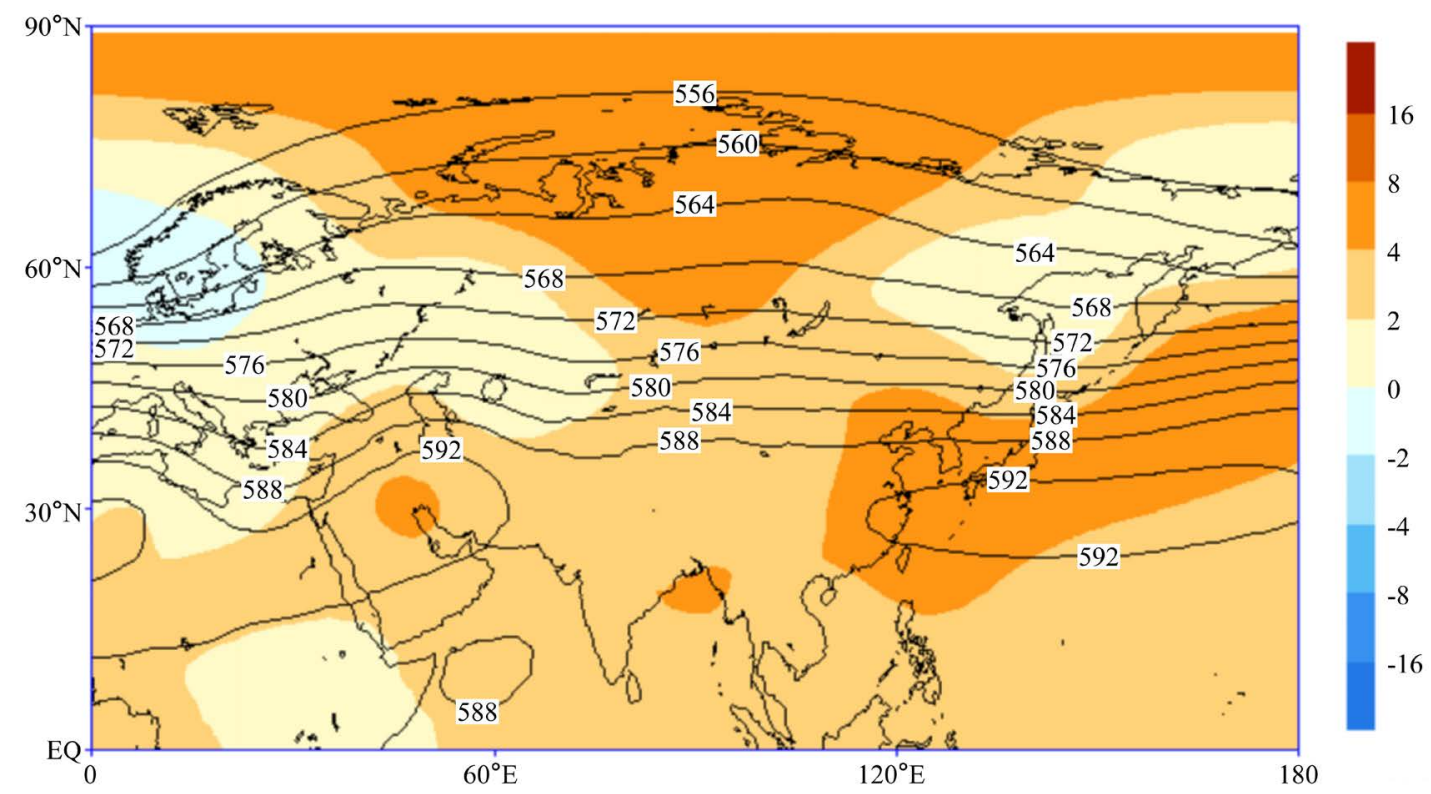

Figure 2. The $500 \mathrm{hPa}$ geopotential height field and anomaly in July 2020.

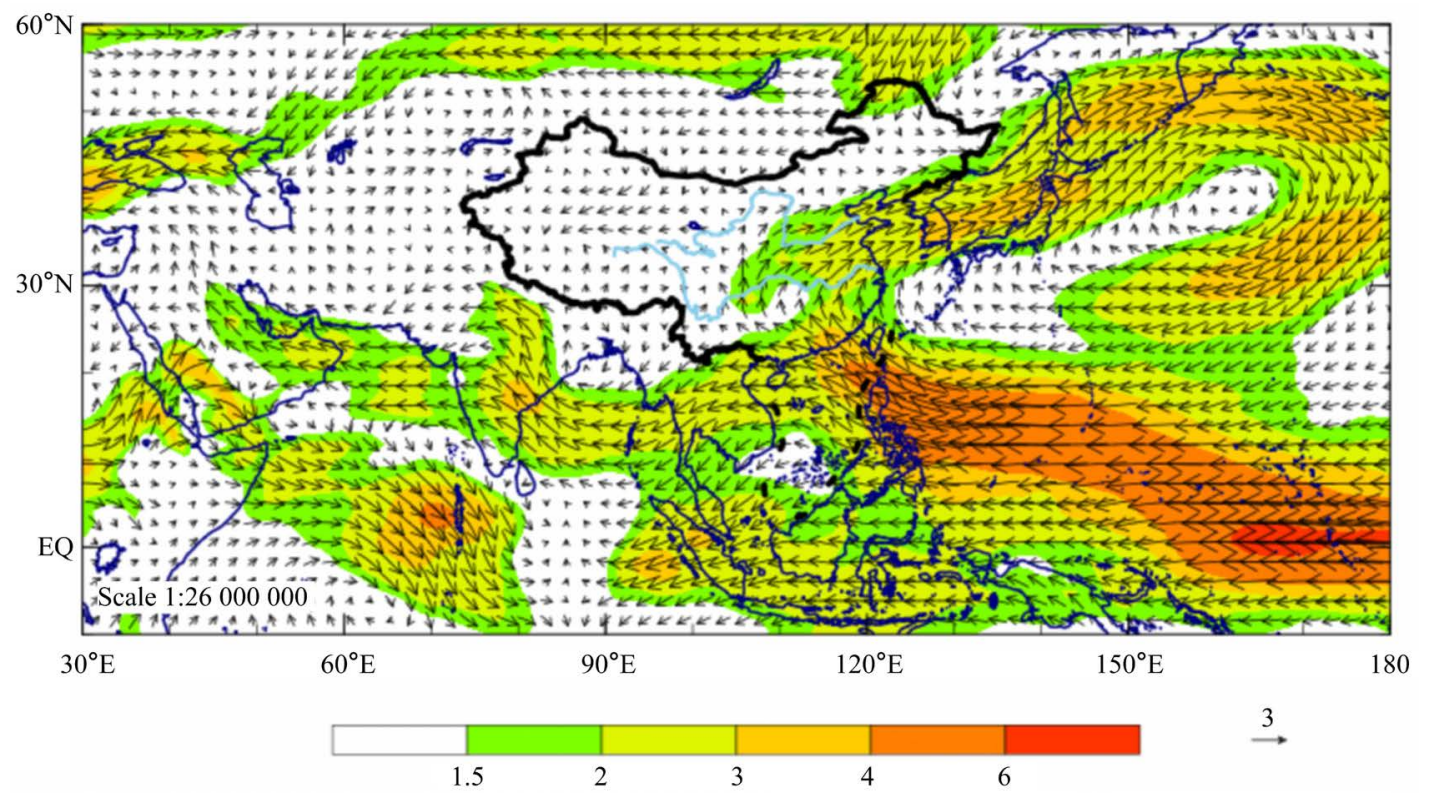

Figure 3. The $850 \mathrm{hPa}$ wind vector and anomaly in July 2020 .

supply of the wind turbine weakened, the convergence of warm and humid water vapor in the Northwest Pacific region weakened, and it was difficult for the monsoon circulation to obtain strong supplementary airflow. Such a large-scale flow field environment is not conducive to the formation and development of the equatorial convergence zone and the tropical monsoon trough, thereby inhibiting the generation of typhoons, making it difficult to generate typhoons.

At the same time, there are abnormally strong positive vorticity flow fields in the low altitudes of East Asia and the Northwest Pacific. The anticyclonic circulation has a larger expansion compared with the same period in previous years, 
and the intensity also has a larger positive anomaly, especially at $120^{\circ} \mathrm{E}-180^{\circ}$ area. The strong east wind formed an unusually large clockwise vorticity circulation. The expansion area of the subtropical high coincides with the average path area of the typhoon. Under the control of the sinking airflow, the frequency of typhoon generation has dropped significantly, causing the "no-typhoon" event in July 2020.

\section{Conclusion}

The frequency of generated typhoons from 1951 to July 2020 showed a slow downward trend. The number of typhoons concentrated in 3 - 5, and the frequency of landed typhoons in China showed a slow upward trend, concentrated in 1 - 3. This study found that the "no-typhoon" event in July has a periodic pattern of about 20 years. Typhoon frequency has a relatively strong negative correlation with the intensity of the subtropical high in the western Pacific, North America, North Africa, and the Atlantic in the northern hemisphere, Typhoon frequency also has a strong negative correlation with the area index and intensity index of the subtropical high in the South China Sea. Meanwhile, it also has a strong negative correlation with typhoon frequency.

In July 2020, the area and intensity of the subtropical high in the Northwest Pacific Ocean were abnormally large and strong, causing the tropical ocean surface to be controlled by the sinking airflow, making it extremely difficult to generate typhoons. The easterly wind prevails in tropical areas in July 2020, and the cross-equatorial airflow is weak, making it difficult to form the tropical monsoon trough and the equatorial convergence zone where the typhoon is born, which will significantly affect the frequency of typhoon generation.

\section{Conflicts of Interest}

The author declares no conflicts of interest regarding the publication of this paper.

\section{References}

Bengtsson, L., Hodges, K. I., Esch, M. et al. (2007). How May Tropical Cyclones Change in a Warmer Climate? Tellus A: Dynamic Meteorology and Oceanography, 59, 539-561. https://doi.org/10.1111/j.1600-0870.2007.00251.x

Camp, J., Roberts, M. J., Comer, E. et al. (2019). The Western Pacific Subtropical High and Tropical Cyclone Landfall: Seasonal Forecasts Using the Met Office GloSea5 System. Quarterly Journal of the Royal Meteorological Society, 145, 105-116. https://doi.org/10.1002/qj.3407

He, C. X., Long, W. J., \& Zhu, F. F. (2012). Probability Theory and Mathematical Statistics (p. 79). Beijing: Higher Education Press.

He, X. Z., \& Gong, D. (2002). Interdecadal change in Western Pacific Subtropical High and Climatic Effects. Journal of Geographical Sciences, 2, 79-86.

Hu, C. L., Lin, R., Jiao, M. et al. (2020). Study on the Characteristics of the First Frost and Its Forecast Model in Liaoning Province. Jiangsu Agricultural Sciences, 48, 276-281. 
Liu, G. L., Li, X., Wang, J. H., Kou, Y., \& Wang X. P. (2020). Research on the Statistical Characteristics of Typhoon Frequency. Ocean Engineering, 209, 107-109. https://doi.org/10.1016/j.oceaneng.2020.107489

Lu, X. J., Dong, C. M., \& Li, G. (2018). The Frequency of Typhoons Entering the East China Sea from 1951 to 2015 and Changes in Landing Points. Acta Atmospheric Sciences, 41, 433-440.

Luo, H. Q. (2016). Market Research and Forecast (2nd ed.). Beijing: Tsinghua University Press.

Su, H. L., Dong, G. H., Wang, M., Yuan, L. W., \& Fei, X. C. (2020). Analysis of the Main Characteristics and Disaster Causes of Landfall Typhoons from 1949 to 2018. Environmental Science and Management, 45, 128-131.

Wu, T. W., Song, L. C., Liu, X. W. et al. (2013). Operational Progress of the Short-Term Climate Prediction Model System of the National Climate Center. Journal of Applied Meteorology, 24, 533-543.

Zhang, D. Q., Zheng, Z. H., Chen, L. J., \& Zhang, P. Q. (2019). Advances on the Predictability and Prediction Methods of 10-30 d Extended Range Forecast. Journal of Applied Meteorological Science, 30, 416-430. https://doi.org/10.12677/AG.2019.96052

Zheng, H. Y., Wu, L., Wen, Z. P., \& Wang, T. M. (2013). Typhoon Frequency Anomaly in the Northwest Pacific and Its Relationship with Air-Sea Flux. Acta Oceanologica Sinica (Chinese Edition), 35, 47-55. 